\title{
WWC1 promotes podocyte survival via stabilizing slit diaphragm protein dendrin
}

\author{
TING LIN*, LI ZHANG*, SHUANGXIN LIU, YUANHAN CHEN, \\ HONG ZHANG, XINGCHEN ZHAO, RUIZHAO LI, QIANMEI ZHANG, RUYI LIAO, \\ ZONGSHUN HUANG, BIN ZHANG, WENJIAN WANG, XINLING LIANG and WEI SHI \\ Division of Nephrology, Guangdong General Hospital, \\ Guangdong Academy of Medical Sciences, Guangzhou, Guangdong 510080, P.R. China
}

Received January 3, 2017; Accepted August 7, 2017

DOI: $10.3892 / \mathrm{mmr} .2017 .7708$

\begin{abstract}
Previous studies have indicated that glomerular podocyte injury serves a crucial role in proteinuria during the process of chronic kidney disease. The slit diaphragm of podocytes forms the final barrier to proteinuria. Dendrin, a constituent of the slit diaphragm protein complex, has been observed to relocate from the slit diaphragm to the nuclei in injured podocytes and promote podocyte apoptosis. However, the exact mechanism for nuclear relocation of dendrin remains unclear. The expression of WWC1 in podocyte injury induced by lipopolysaccharides (LPS) or adriamycin (ADR) was detected by reverse transcription-quantitative polymerase chain reaction (RT-qPCR), western blotting and the immunofluorescence assay. The role of WWC1 in podocyte apoptosis was detected by knockdown of WWC1 and flow cytometry. The mRNA and protein expression levels of apoptosis-associated genes Bcl-2-associated X (Bax) and Bcl-2 were measured by RT-qPCR and western blotting. The impact of WWC1 on dendrin nucleus relocation in vitro in podocytes was further evaluated by knockdown of WWC1. Expression of WWC1 significantly decreased in injured podocytes in vitro. The loss-of-function assay indicated that knockdown of WWC1 gene in vitro promoted podocyte apoptosis, accompanied with increased levels of the pro-apoptotic protein Bax and decreased levels of the anti-apoptotic protein Bcl-2. Furthermore, the relocation of dendrin protein was significantly promoted by knockdown of the WWC1 gene. In conclusion, the study indicated that loss of WWC1 may contribute to podocyte
\end{abstract}

Correspondence to: Dr Xinling Liang or Professor Wei Shi, Division of Nephrology, Guangdong General Hospital, Guangdong Academy of Medical Sciences, 106 Zhongshan Road, Guangzhou, Guangdong 510080, P.R. China

E-mail: xinlingliang_ggh@163.com

E-mail: shiweigd139@163.com

*Contributed equally

Key words: WWC1, dendrin, podocyte, slit diaphragm, apoptosis apoptosis by inducing nuclear relocation of dendrin protein, which provided novel insight into the molecular events in podocyte apoptosis.

\section{Introduction}

The glomerular podocyte functions as a charge barrier to prevent proteinuria. Proteinuira is the most critical clinical signature of podocyte injury predominantly by anatomical and molecular abnormalities of podocyte foot processes (FP) and the interposed slit diaphragm (SD) (1). The consistent proteinuria and podocyte apoptosis damages glomerular structure and results in progressive glomerular consecutive tubular destruction $(2,3)$, resulting in chronic kidney disease (CKD), which is a worldwide health problem, of which the prevalence is increasing (4). Due to the fact that CKD is a worldwide chronic disease and annually millions die of cardiovascular or renal complications directly due to CKD, exploring factors intervening in the pathogenesis of podocyte injury is necessary in the development of novel strategies for CKD clinical therapy.

Previous genetic studies have highlighted the molecular makeup of SD and podocyte FP (5-6). SD is comprised by molecular proteins functioning as 'protein gatekeepers' in the junctional domain of the podocyte. The first observed SD protein, Nephrin, was identified by Ruotsalainen et al (7) in 1999, and more recently additional and more complex SD proteins have been identified, including podocin, CD2 associated protein (CD2AP), nephrin-like protein 1, zona occludens 1 and dendrin (8-11). Certain SD proteins have been identified to be critical in renal injury; genetic deletion of CD2AP, a scaffolding protein at the $\mathrm{SD}$, leads to progressive renal failure in mice $(12,13)$, and ectopic expression of CD2AP in podocyte prevents the development of proteinuria $(14,15)$. Dendrin, another newly identified SD complex, interacts with CD2AP, and loss of CD2AP could drive dendrin protein from the SD to the nucleus (16). Nuclear relocation of dendrin has been identified in various podocyte injury models in vitro and in human renal diseases $(17,18)$. In addition, nuclear dendrin could further promote apoptosis of podocytes (19). Despite of these results, the precise molecular mechanism by which dendrin regulates function of podocyte remains to be fully understood. 
In yeast two hybrid screens with the human isoform of dendrin, Kremerskothen et al (20) isolated a cDNA coding for a novel protein, WWC1 (also termed KIBRA) (20). WWC1, a kidney- and brain-associated protein, was observed to be predominantly expressed in the brain and kidney, and in the kidney, WWC1 was identified to be expressed in glomerular podocytes, tubular structures and collecting ducts (21). WWC1, interaction directly with protein associated to tight junctions (PATJ), impacted the proteins associated with Lin seven-PATJ-Crumbs 3 cell polarity complex and modulated the migration of podocytes (21). However, the bio-function of WWC1 in the podocytes remains to be fully elucidated, and the functional association between WWC1 and dendrin in the podocytes was investigated in the current study.

In the present study, it was indicated that expression of WWC1 significantly was decreased in injured podocytes. Further investigation indicated that loss of WWC1 in vitro directly induced podocyte apoptosis and promoted SD protein dendrin relocation from SD into the nuclei. The results present novel insight into the molecular events in podocyte injury.

\section{Materials and methods}

Cell cultures. The conditionally immortalized mouse podocyte cell line (MPC-5) was donated by Dr Jochen Reiser (Rush University Medical Center, Chicago, IL, USA), and cultured as described previously (22-23). Cells were treated with adriamycin (ADR; Santa Cruz Biotechnology, Inc., Santa Cruz, CA, USA) in RPMI-1640 medium (Thermo Fisher Scientific, Inc., Waltham, MA, USA) to a final concentration of $0.25 \mu \mathrm{g} / \mathrm{ml}$ or of lipopolysaccharides (LPS; Sigma Aldrich; Merck KGaA, Darmstadt, Germany) to $1 \mu \mathrm{g} / \mathrm{ml}$ for $24 \mathrm{~h}$. Equal amounts of phosphate-buffered saline (PBS) were treated as the negative control.

siRNA transfection. Oligonucleotide siRNA was synthesized by Guangzhou RiboBio Co., Ltd. (Guangzhou, China). WWC1 or scramble siRNA (Scr) was transfected into podocytes using Lipofectamine $^{\circledR} 2000$ reagent (Invitrogen; Thermo Fisher Scientific, Inc.) following the manufacturer's protocol. WWC1 siRNA sequences used were as follows: 5'-GCACAGAGA CCAGGUACUUdTdT-3', 5'-GCACAAGAGUGAGUUGCA AdTdT-3' and 5'-GGUGGACAGAGAGACCAAUdTdT-3'.

Reverse transcription-quantitative polymerase chain reaction $(R T-q P C R)$. RNA samples were prepared using TRIzol RNA isolation system (Invitrogen; Thermo Fisher Scientific, Inc.) and were reverse transcribed into cDNA (50 ng) using superscript reverse transcriptase. The cDNA was used for RT-qPCR analysis using a Platinum SYBR-Green SuperMix-UDG kit (Takara Bio, Inc., Otsu, Japan) as described previously (21). The primer sequences used are listed as follows: WWC1, forward 5'-TGCTGAGGGAAACCAAAGCC-3' and reverse 5'-CTGGACCATAGGTCGGAGTG-3'; Bcl-2-associated X (Bax), forward, 5'-CTGGACCATAGGTCGGAGTG-3' and reverse 5'-AATTCGCCGGAGACACTCG-3'; Bcl-2, forward 5'-TGTGGCCTGATGTTGGATAAC-3' and reverse 5'-GGT GACGAATGTGCAAATCTACT-3'; GAPDH, forward 5'-AGGTCGGTGTGAACGGATTTG-3' and reverse 5'-TGT AGACCATGTAGTTGAGGTCA-3'.
Immunofluorescence of cultured podocytes. Subsequent to being subjected to various treatments, podocytes were fixed with $4 \%$ paraformaldehyde at $-20^{\circ} \mathrm{C}$ for $20 \mathrm{~min}$, then were blocked using blocking solution of $5 \%$ fetal calf serum (Gibco; Thermo Fisher Scientific, Inc.) in PBS. The primary antibodies were incubated overnight at $4^{\circ} \mathrm{C}$, followed by $1 \mathrm{~h}$ of incubation with goat anti-rabbit Alexa Fluor 488 (4412S; 1:1,000; Cell Signaling Technology, Inc., Danvers, MA, USA) or Texas red-donkey anti-goat IgG (ab6883; 1:250; Abcam, Cambridge, MA, USA) at room temperature. DAPI (1:1,000; Sigma-Aldrich; Merck KGaA) was stained for counterstaining. The primary antibodies used in the present study were as follows: Rabbit anti-WWC1 (sc-133374; 1:100; Santa Cruz Biotechnology, Inc.), rabbit anti-dendrin (ABT59; 1:400; EMD Millipore, Billerica, MA, USA) and goat anti-dendrin (sc-167616; 1:100; Santa Cruz Biotechnology, Inc.). All images were analyzed by two investigators blinded to the identity of the samples.

Western blotting. Protein lysates were resolved by SDS (7.5-10\%)-polyacrylamide gel electrophoresis, transferred onto a polyvinylidene difluoride membrane, and hybridized with the corresponding antibodies. The membranes were washed 3 times for 5 min with PBS following antibody incubation. The antibodies used in the present study were as follows: Rabbit anti-WWC1 (sc-133374; 1:500; Santa Cruz Biotechnology, Inc.), rabbit anti-dendrin (ABT59; 1:1,000; EMD Millipore), rabbit anti-Bax (sc-493; 1:500; Santa Cruz Biotechnology, Inc.), rabbit anti-Bcl-2 (3498; 1:1,000; Cell Signaling Technology, Inc.), rabbit anti-GAPDH (G9545; 1:5,000; Sigma-Aldrich; Merck KGaA) and rabbit anti-histone (4499; 1:2,000; Cell Signaling Technology, Inc.). The membrane was then incubated with anti-rabbit or anti-mouse IgG (211002217 and 515005071; 1:10,000; Jackson ImmunoResearch Laboratories, Inc., West Grove, PA, USA) at room temperature for $1 \mathrm{~h}$. Enhanced chemiluminescence (Pierce Biotechnology, Inc., Rockford, IL, USA) reagents were used for detection.

Annexin V and propidium iodide (PI) staining. Apoptotic cells were determined using an Annexin V/PI apoptosis detection kit (Nanjing KeyGEN Biotech., Co., Ltd., Nanjing, China) as described previously (20).

Statistical analysis. The statistical analysis was performed using SPSS 15.0 (SPSS, Inc., Chicago, IL, USA). All experiments in vitro were performed at least in triplicate. Continuous values were expressed as mean \pm standard error using one-way analysis of variance and Bonferroni non-parametric test for statistical comparisons. $\mathrm{P}<0.05$ was considered to indicate a statistically significant difference.

\section{Results}

Expression of WWCl was decreased in injured podocytes in vitro. In order to evaluate whether loss of WWC1 could be induced by ADR or LPS stimulation particularly in podocytes, WWC1 expression was assessed under different exposures by RT-qPCR, immunoblotting and immunofluorescence staining. The time-response experiment 
A
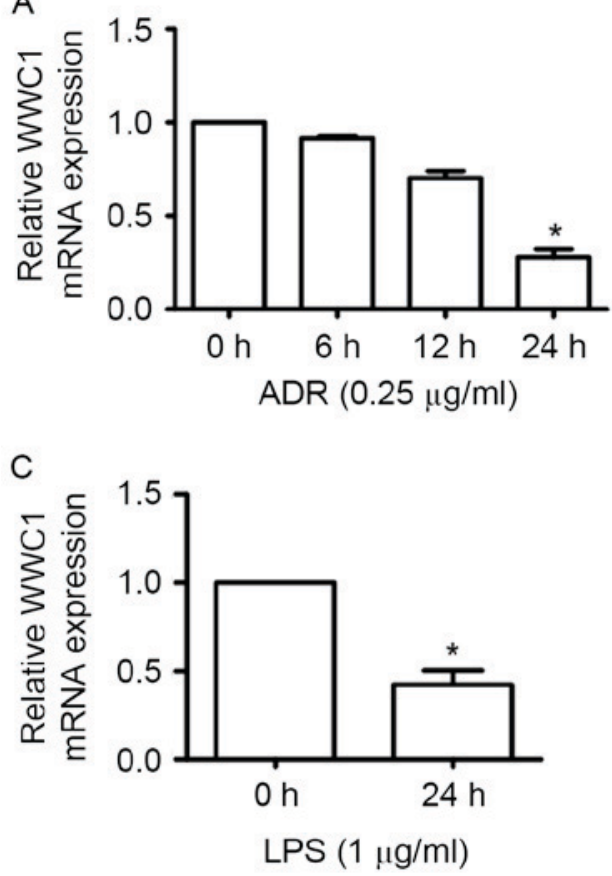

B

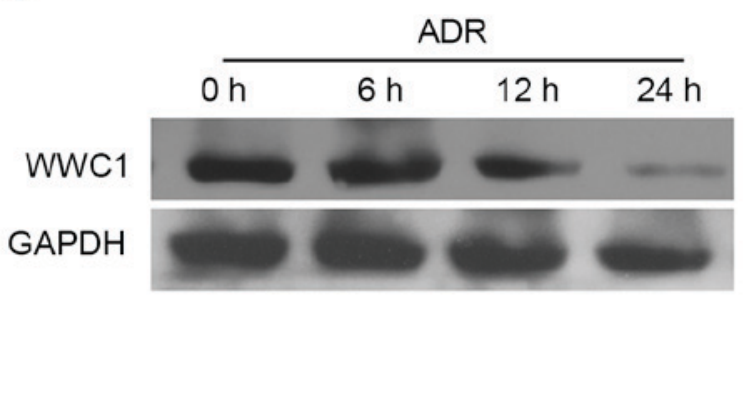

$\mathrm{D}$

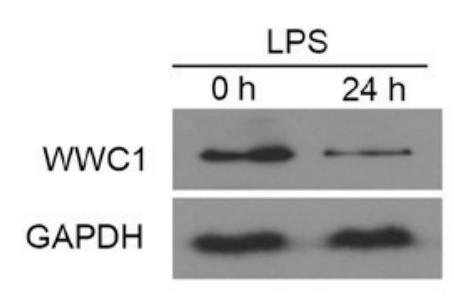

E

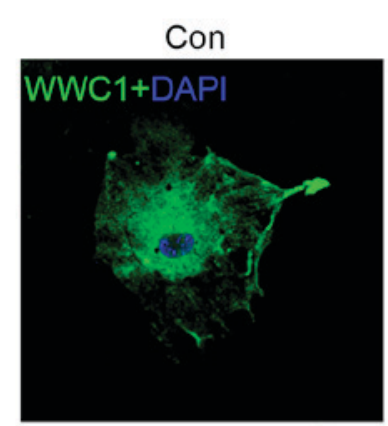

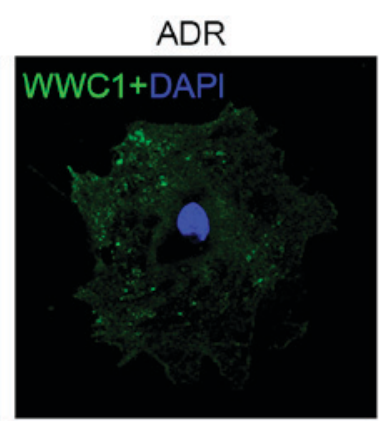

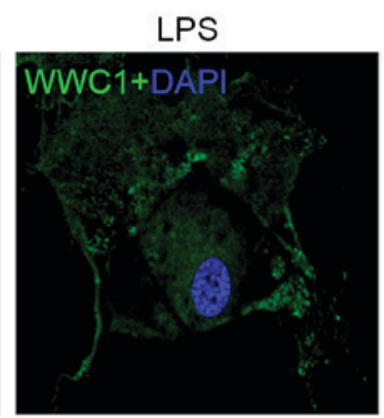

Figure 1. Expression of WWC1 is decreased in injured podocytes in vitro. (A) Podocytes were treated with ADR at a dose of $0.25 \mu \mathrm{g} / \mathrm{ml}$, and RT-qPCR was performed to measure gene expression of WWC1 in different time points. (B) Representative western blots of WWC1 expression in podocyte treated as described in (A). (C and D) Podocytes were treated with LPS at a dose of $1 \mu \mathrm{g} / \mathrm{ml}$ or an equal amount of PBS. Gene and protein expression of WWC1 were measured by RT-qPCR and western blotting, respectively. (E) Representative immunofluorescence images of podocyte staining by anti-WWC1 antibodies under different exposure. Original magnification, $\mathrm{x} 400$. Analysis of variance, ${ }^{*} \mathrm{P}<0.05$ vs. time $0 \mathrm{~h}$. ADR, adriamycin; RT-qPCR, reverse transcription-quantitative polymerase chain reaction; LPS, lipopolysaccharides.

indicated that ADR induced loss of WWC1 expression in a time-dependent manner. A significant decrease of WWC1 gene and protein expression was observed following $24 \mathrm{~h}$ exposure to $0.25 \mu \mathrm{g} / \mathrm{ml}$ of ADR (Fig. 1A and B). Following stimulation by LPS $(1 \mu \mathrm{g} / \mathrm{ml})$ for $24 \mathrm{~h}$, WWC1 expression significant decreased in cultured podocyte (Fig. 1C and D). Similar results also indicated that ADR and LPS stimulation induced WWC1 expression reduction by immunofluorescence staining (Fig. 1E) $(\mathrm{P}<0.05)$.

Loss of WWC1 directly induced podocyte apoptosis in vitro. In order to investigate the direct affection of WWC1 in podocyte, WWC1 gene expression was altered in podocytes in vitro by WWC1 siRNA. Three pairs of WWC1 siRNA were transfected into podocytes and RT-qPCR was performed to detect WWC1 gene expression $48 \mathrm{~h}$ subsequent to transfection. Gene and protein analysis of the apoptotic factor Bax exhibited increased expression in WWC1-silenced podocytes (Fig. 2A and B), while the anti-apoptotic factor Bcl-2 was reduced (Fig. 2A and C). Annexin V and PI staining assay indicated that loss of WWC1 directly induced apoptosis process in podocytes $(2.56 \pm 0.34$ vs. $10.67 \pm 0.88$ and $13.60 \pm 3.19$, respectively; $\mathrm{n}=3$ ) (Fig. $2 \mathrm{D}$ and $\mathrm{E})(\mathrm{P}<0.05)$.

Loss of WWC1 induced dendrin nucleus relocation in podocytes. As we know, nucleus relocation of SD protein dendrin is one of the newly confirmed apoptotic mechanisms in podocytes (19). Considering the interactions between WWC1 and dendrin in normal podocytes, subcellular localization of dendrin in podocytes was assessed with silenced WWC1 gene. Notably, following silencing of the WWC1 gene in podocytes, dendrin nuclear accumulation was significantly increased (Fig. 3A and B). By immunofluorescence staining, it was identified that WWC1 and dendrin were co-located in the cytoplasm, with low levels in the nuclei of the physiological podocyte, whereas an accumulation of dendrin was detected in the podocyte nuclei in WWC1 silenced podocytes (Fig. 3C). These results indicate that loss of WWC1 could directly drive dendrin relocating into the nuclei of podocyte. 

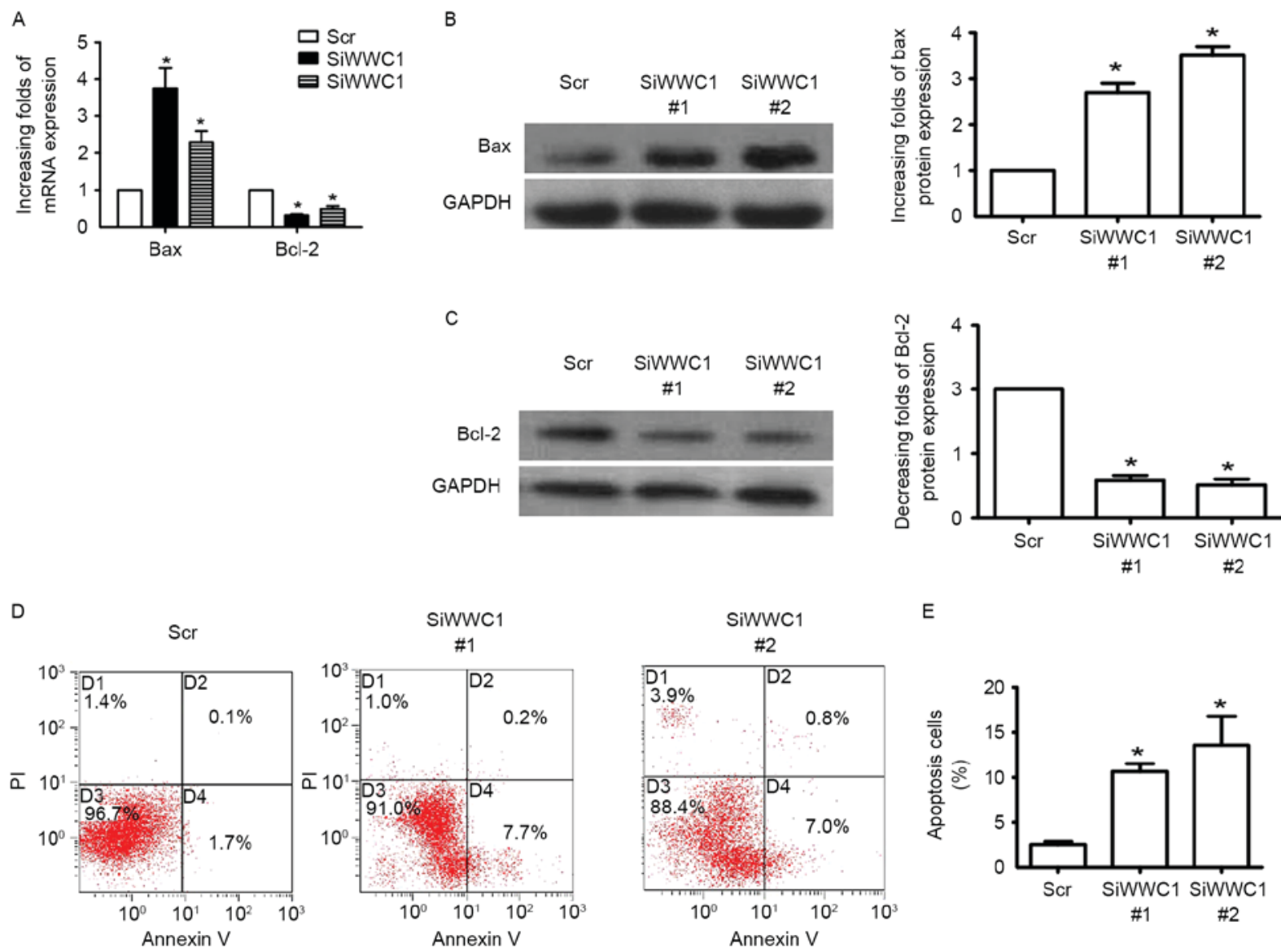

$\mathrm{E}$

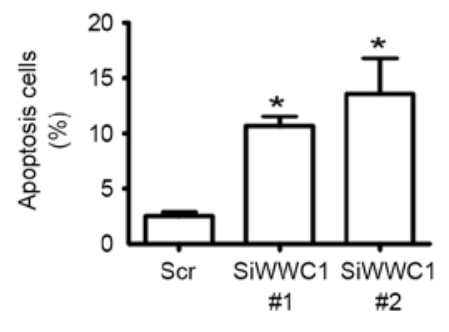

Figure 2. Loss of WWC1 directly induces podocyte apoptosis in vitro. (A) Podocytes were transfected with WWC1 siRNA or Scr. RT-qPCR was performed to analyze the expression of WWC1 in podocytes. Gene expression of apoptosis-associated genes Bax and Bcl-2 were determined by RT-qPCR. (B and C) Protein expression levels of Bax and Bcl-2 were determined by western blotting, respectively. (D) Apoptosis cells were measured by flow cytometry using Annexin $\mathrm{V}$ and PI staining $48 \mathrm{~h}$ after siRNA transfection. (E) The percentage of apoptotic cells were measured. All data are expressed as the mean \pm standard error of three independent experiments. Analysis of variance, ${ }^{*} \mathrm{P}<0.05$ vs. Scr. siRNA, small interfering RNA; Scr, scramble siRNA; Bax, Bcl-2-associated X; RT-qPCR, reverse transcription-quantitative polymerase chain reaction; PI, propidium iodide.

\section{Discussion}

The terminally differentiated podocyte functions as a critical barrier to prevent proteinuria, and proteinuria is the clinical signature for podocyte injury, with or without loss of renal functions. Emerging experimental and clinical studies have highlighted that loss of podocyte directly causes proteinuria and glomerulosclerosis, owing to podocyte apoptosis or detachment (24-27). The present study demonstrated, to the best of our knowledge for the first time, that kidney and brain associated protein WWC1, is a critical molecular in podocyte injury. Reduced WWC1 expression was identified in injured podocytes, and loss of WWC1 directly induced podocyte apoptosis. In addition further evidence was obtained that WWC1 protected podocytes from apoptosis by preventing SD protein dendrin from relocating into nuclei.

The expression of WWC1 (KIBRA), the mammalian ortholog of Kibra, has been observed to be enriched in kidney and brain (18). In Drosophila, Kibra predominantly acts in the Merlin branch upstream of the core kinase cascade to regulate Hippo signaling, a well-recognized pathway by restricting proliferation and promoting apoptosis (28-30). In mammals, WWC1 additionally exhibits MST-independent functional regulation of Hippo signaling pathway in breast cancer (31). In a breast cancer cell line, loss of WWC1 expression displays epithelial-to-mesenchymal transition features as well as promoted migration. Directional migration regulation is additionally observed in podocytes (21). The current study focused on the observation of the response of WWC1 to podocyte apoptosis injury. A reduction of WWC1 expression was observed in ADRand LPS-mediated podocyte injury. Due to the fact that ADR and LPS induce proteinuria in mice, these results indicated a probable endogenic protective role of WWC1 in podocytes.

Apoptosis has been reported to cause podocyte loss and glomerulosclerosis, and according to the biogenetic pleiotropy of WWC1 (31-34), it was hypothesized that reduction of WWC1 may be associated with podocyte apoptosis as a response to injury. Subsequently, it was investigated whether loss of WWC1 directly induces podocyte apoptosis. Increased apoptotic cells were observed following knockdown of endogenic WWC1 gene in podocyte by Annexin V and PI staining. In addition, the apoptosis-associated gene $\mathrm{Bax}$ and $\mathrm{Bcl}-2$ were observed to be activated and inhibited respectively with WWC1 gene silencing.

These results suggested that endogenic WWC1 could serve a critical role in protecting podocytes from apoptotic injury. Total podocyte number is a balance between proliferation and loss, owing to several critical processes including DNA synthesis, DNA damage, hypertrophy, detachment and 
A

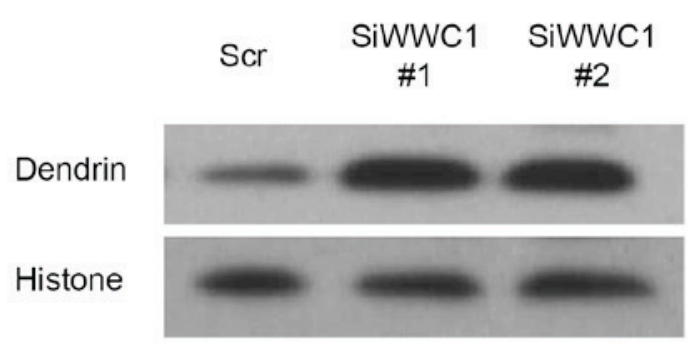

C
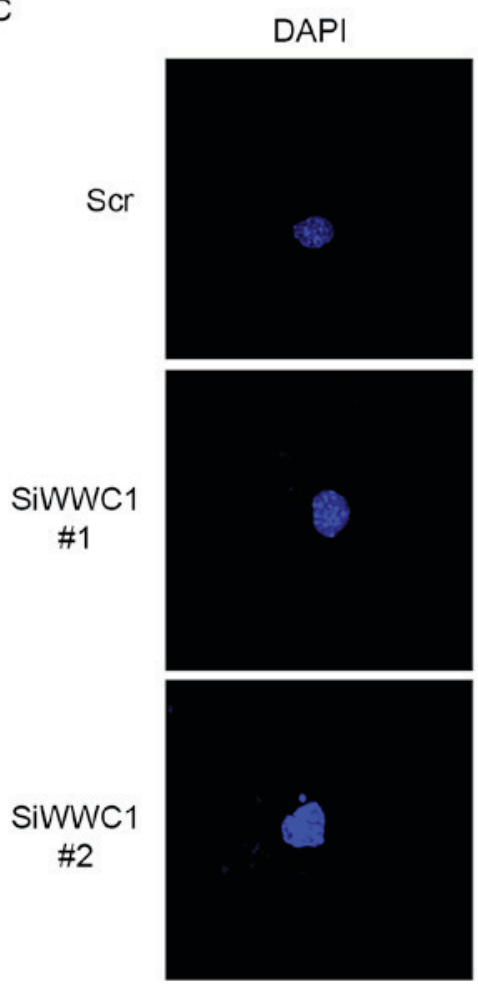
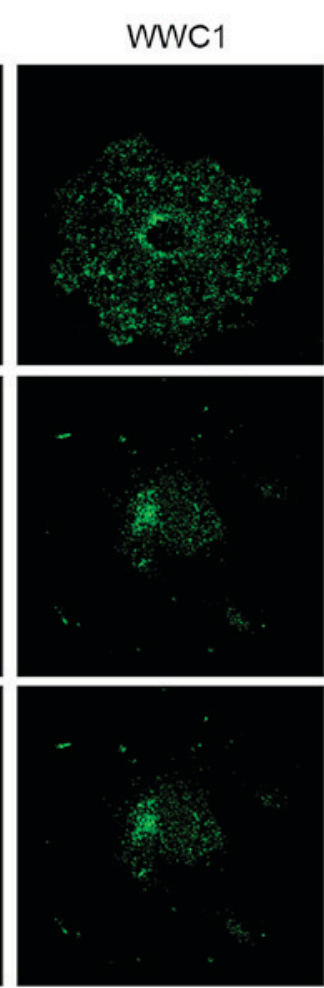

$\mathrm{B}$

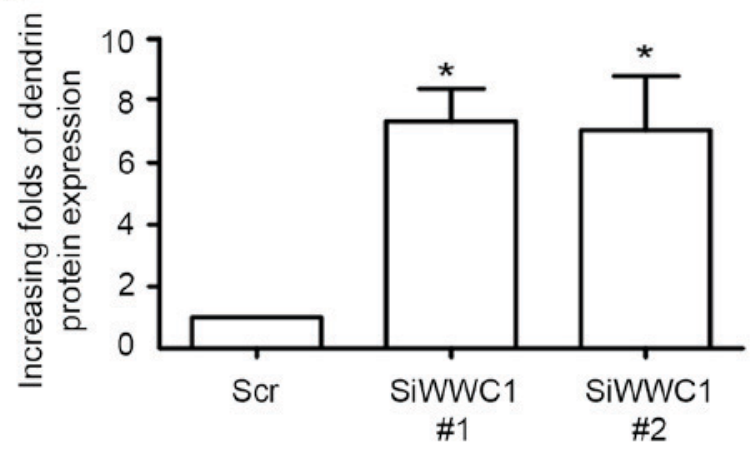

Dendrin
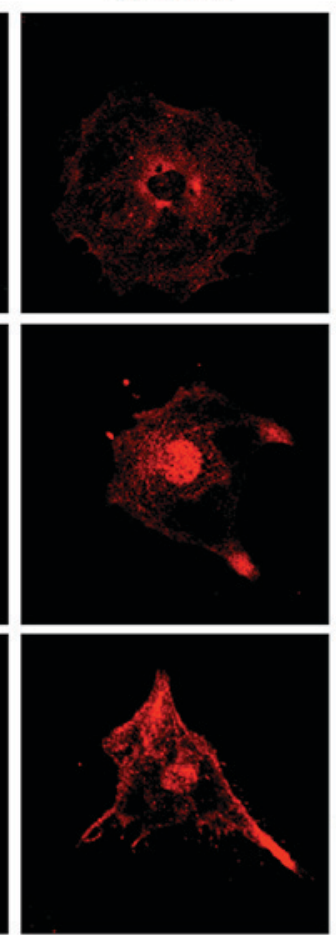
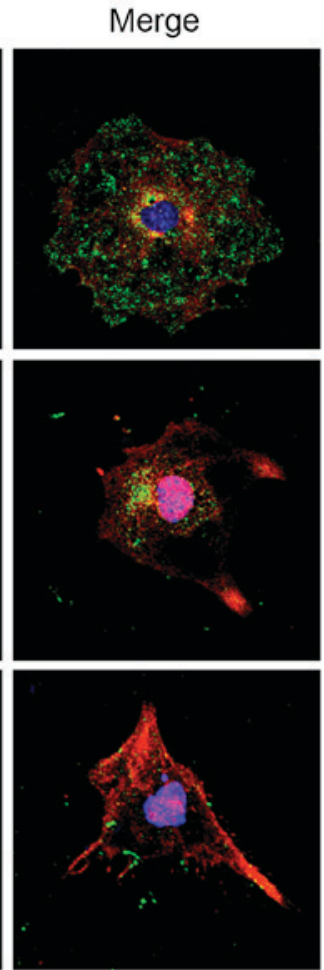

Figure 3. WWC1 impacts dendrin nucleus relocation in podocyte. (A and B) Podocytes were transfected with WWC1 siRNA or scramble siRNA. Podocytes with either WWC1 or scramble siRNA transfection were lysated and nuclear protein was extracted using the nuclear and cytoplasmic protein extraction kit. Nucleus dendrin expression was measured by western blotting, using histone 3 as equivalent loads in the nuclei. (C) Representative photographs of triple staining of DAPI, WWC1 and dendrin showing nucleus relocation of dendrin in podocytes with silenced WWC1 gene (original magnification, $\mathrm{x} 400$ ). Analysis of variance, ${ }^{*} \mathrm{P}<0.05$, vs. Scr. siRNA, small interfering RNA; Scr, scramble siRNA.

apoptosis. The proteins or molecules those are stably present in podocyte are essential for normal function, such as survival. For example, several SD proteins, such as CD2AP and nephrin, had been demonstrated to serve a critical role in proteinuria protection $(35,36)$. The results provide new evidence supporting the role of WWC1 in podocyte protection.

The mechanisms of WWC1 in the protection of podocyte from apoptosis require further investigation. WWC1 was originally isolated by dendrin in a yeast two hybrid screen (20), and accumulating evidence has indicated that dendrin is additionally one of the SD complex proteins present in podocytes $(37,38)$. Nuclear relocation of dendrin has been identified both in human glomerular diseases and various podocyte injury models, and notably, it was observed that nuclear dendrin induced podocyte apoptosis $(17,18)$. It was investigated whether WWC1 could contribute to normal location of dendrin in the SD domain; it was identified that loss of WWC1 in podocytes directly promoted movement of dendrin proteins from SD into the nuclei, indicating that WWC1 is a crucial molecular component in regulating the stabilization of dendrin in podocytes.

The present study systematically evaluated the functions of WWC1 in the podocyte. The results demonstrated that expression of WWC1 was significantly decreased in injured podocytes. In addition, loss of WWC1 in podocytes directly induced apoptosis of podocytes. Nuclear relocation of the SD complex protein dendrin was promoted following WWC1 gene silencing in podocytes. These results indicate that endogenic WWC1 could serve a critical role in podocyte apoptosis. Taken together, the results demonstrate that WWC1 may serve as a promising molecular target to tackle proteinuric kidney diseases. 


\section{Acknowledgements}

The present study was supported by the National Nature and Science Grants (grant nos. 81270784, 181470930 and 81500560); Nature and Science Grant of Guangdong Province (grant nos. 2014A030310106 and 2014A030310107) and National Clinical Key Specialty Construction Projects.

\section{References}

1. Somlo S and Mundel P: Getting a foothold in nephrotic syndrome. Nat Genet 24: 333-335, 2000

2. Schwartz MM: The role of podocyte injury in the pathogenesis of focal segmental glomerulosclerosis. Ren Fail 22: 663-684, 2000

3. Kriz W and Lemley KV: The role of the podocyte in glomerulosclerosis. Curr Opin Nephrol Hypertens 8: 489-497, 1999.

4. Schieppati A and Remuzzi G: Chronic renal diseases as a public health problem: Epidemiology, social, and economic implications. Kidney Int Suppl (Suppl): S7-S10, 2005.

5. Kawachi H, Han GD, Miyauchi N, Hashimoto T, Suzuki K and Shimizu F: Therapeutic targets in the podocyte: Findings in anti-slit diaphragm antibody-induced nephropathy. J Nephrol 22: 450-456, 2009.

6. Kriz W and Lemley KV: Potential relevance of shear stress for slit diaphragm and podocyte function. Kidney Int 91: 1283-1286, 2017.

7. Ruotsalainen V, Ljungberg P, Wartiovaara J, Lenkkeri U, Kestilä M, Jalanko H, Holmberg C and Tryggvason K: Nephrin is specifically located at the slit diaphragm of glomerular podocytes. Proc Natl Acad Sci USA 96: 7962-7967, 1999.

8. Roselli S, Gribouval O, Boute N, Sich M, Benessy F, Attié T, Gubler MC and Antignac C: Podocin localizes in the kidney to the slit diaphragm area. Am J Pathol 160: 131-139, 2002.

9. Schwarz K, Simons M, Reiser J, Saleem MA, Faul C, Kriz W, Shaw AS, Holzman LB and Mundel P: Podocin, a raft-associated component of the glomerular slit diaphragm, interacts with CD2AP and nephrin. J Clin Invest 108: 1621-1629, 2001.

10. Shih NY, Li J, Cotran R, Mundel P, Miner JH and Shaw AS: $\mathrm{CD} 2 \mathrm{AP}$ localizes to the slit diaphragm and binds to nephrin via a novel C-terminal domain. Am J Pathol 159: 2303-2308, 2001.

11. Ahola H,Heikkilä E, Aström E, Inagaki M, Izawa I, Pavenstädt H, Kerjaschki D and Holthöfer H: A novel protein, densin, expressed by glomerular podocytes. J Am Soc Nephrol 14: 1731-1737, 2003.

12. Kim JM, Wu H, Green G, Winkler CA, Kopp JB, Miner JH, Unanue ER and Shaw AS: CD2-associated protein haploinsufficiency is linked to glomerular disease susceptibility. Science 300: 1298-1300, 2003.

13. Shih NY, Li J, Karpitskii V, Nguyen A, Dustin ML, Kanagawa O, Miner JH and Shaw AS: Congenital nephrotic syndrome in mice lacking CD2-associated protein. Science 286: 312-315, 1999.

14. Huber TB, Kwoh C, Wu H, Asanuma K, Gödel M, Hartleben B, Blumer KJ, Miner JH, Mundel P and Shaw AS: Bigenic mouse models of focal segmental glomerulosclerosis involving pairwise interaction of CD2AP, Fyn, and synaptopodin. J Clin Invest 116: $1337-1345,2006$.

15. Grunkemeyer JA, Kwoh C, Huber TB and Shaw AS: CD2-associated protein (CD2AP) expression in podocytes rescues lethality of CD2AP deficiency. J Biol Chem 280: 29677-29681, 2005.

16. Yaddanapudi S, Altintas MM, Kistler AD, Fernandez I, Möller CC, Wei C, Peev V, Flesche JB, Forst AL, Li J, et al: $\mathrm{CD} 2 \mathrm{AP}$ in mouse and human podocytes controls a proteolytic program that regulates cytoskeletal structure and cellular survival. J Clin Invest 121: 3965-3980, 2011.

17. Asanuma K, Akiba-Takagi M, Kodama F, Asao R, Nagai Y, Lydia A, Fukuda H, Tanaka E, Shibata T, Takahara H, et al: Dendrin location in podocytes is associated with disease progression in animal and human glomerulopathy. Am J Nephrol 33: 537-549, 2011.

18. Kodama F, Asanuma K, Takagi M, Hidaka T, Asanuma E, Fukuda H, Seki T, Takeda Y, Hosoe-Nagai Y, Asao R, et al: Translocation of dendrin to the podocyte nucleus in acute glomerular injury in patients with IgA nephropathy. Nephrol Dial Transplant 28: 1762-1772, 2013.
19. Asanuma K, Campbell KN, Kim K, Faul C and Mundel P: Nuclear relocation of the nephrin and CD2AP-binding protein dendrin promotes apoptosis of podocytes. Proc Natl Acad Sci USA 104: 10134-10139, 2007.

20. Kremerskothen J, Plaas C, Büther K, Finger I, Veltel S, Matanis T, Liedtke $\mathrm{T}$ and Barnekow A: Characterization of KIBRA, a novel WW domain-containing protein. Biochem Biophys Res Commun 300: 862-867, 2003.

21. Duning K, Schurek EM, Schluter M, Bayer M, Reinhardt HC, Schwab A, Schaefer L, Benzing T, Schermer B, Saleem MA, et al: KIBRA modulates directional migration of podocytes. J Am Soc Nephrol 19: 1891-1903, 2008

22. Li R, Zhang L, Shi W, Zhang B, Liang X, Liu S and Wang W: NFAT2 mediates high glucose-induced glomerular podocyte apoptosis through increased Bax expression. Exp Cell Res 319: 992-1000, 2013.

23. Ma J, Zhang B, Liu S, Xie S, Yang Y, Ma J, Deng Y, Wang W, Xu L, Li R, et al: 1,25-dihydroxyvitamin $\mathrm{D}(3)$ inhibits podocyte uPAR expression and reduces proteinuria. PLoS One 8: e64912, 2013.

24. Verzola D, Gandolfo MT, Ferrario F, Rastaldi MP, Villaggio B, Gianiorio F, Giannoni M, Rimoldi L, Lauria F, Miji M, et al: Apoptosis in the kidneys of patients with type II diabetic nephropathy. Kidney Int 72: 1262-1272, 2007.

25. Eid AA, Gorin Y, Fagg BM, Maalouf R, Barnes JL and Benya RV: Mechanisms of podocyte injury in diabetes: Role of cytochrome P450 and NADPH oxidases. Diabetes 58: 1201-1211, 2009.

26. Schiffer M, Bitzer M, Roberts IS, Kopp JB, ten Dijke P, Mundel P and Böttinger EP: Apoptosis in podocytes induced by TGF-beta and Smad7. J Clin Invest 108: 807-816, 2011.

27. Kim YH, Goyal M, Kurnit D, Wharram B, Wiggins J, Holzman L, Kershaw D and Wiggins R: Podocyte depletion and glomerulosclerosis have a direct relationship in the PAN-treated rat. Kidney Int 60: 957-968, 2001.

28. Baumgartner R, Poernbacher I, Buser N, Hafen E and Stocker H: The WW domain protein Kibra acts upstream of Hippo in Drosophila. Dev Cell 18: 309-316, 2010.

29. Genevet A, Wehr MC, Brain R, Thompson BJ and Tapon N: Kibra is a regulator of the Salvador/Warts/Hippo signaling network. Dev Cell 18: 300-308, 2010.

30. Zhao B, Tumaneng K and Guan KL: The Hippo pathway in organ size control, tissue regeneration and stem cell self-renewal. Nat Cell Biol 13: 877-883, 2011.

31. Moleirinho S, Chang N, Sims AH, Tilston-Lünel AM, Angus L, Steele A, Boswell V, Barnett SC, Ormandy C, Faratian D, et al: KIBRA exhibits MST-independent functional regulation of the Hippo signaling pathway in mammals. Oncogene 32: 1821-1830, 2013.

32. Basu-Roy U, Bayin NS, Rattanakorn K, Han E, Placantonakis DG, Mansukhani A and Basilico C: Sox2 antagonizes the Hippo pathway to maintain stemness in cancer cells. Nat Commun 6: 6411, 2015.

33. Papenberg G, Salami A, Persson J, Lindenberger U and Bäckman L: Genetics and functional imaging: Effects of APOE, BDNF, COMT, and KIBRA in aging. Neuropsychol Rev 25: 47-62, 2015.

34. Yang S, Ji M, Zhang L, Chen Y, Wennmann DO, Kremerskothen J and Dong J: Phosphorylation of KIBRA by the extracellular signal-regulated kinase (ERK)-ribosomal S6 kinase (RSK) cascade modulates cell proliferation and migration. Cell Signal 26: 343-351, 2014.

35. Schiffer M, Mundel P, Shaw AS and Böttinger EP: A novel role for the adaptor molecule CD2-associated protein in transforming growth factor-beta-induced apoptosis. J Biol Chem 279: 37004-37012, 2004.

36. Huber TB, Hartleben B, Kim J, Schmidts M, Schermer B, Keil A, Egger L, Lecha RL, Borner C, Pavenstädt H, et al: Nephrin and CD2AP associate with phosphoinositide 3-OH kinase and stimulate AKT-dependent signaling. Mol Cell Biol 23: 4917-4928, 2003.

37. Kremerskothen J, Kindler S, Finger I, Veltel S and Barnekow A: Postsynaptic recruitment of Dendrin depends on both dendritic mRNA transport and synaptic anchoring. J Neurochem 96: 1659-1666, 2006.

38. Patrakka J, Xiao Z, Nukui M, Takemoto M, He L, Oddsson A, Perisic L, Kaukinen A, Szigyarto CA, Uhlén M, et al: Expression and subcellular distribution of novel glomerulus-associated proteins dendrin, ehd3, sh2d4a, plekhh2, and 2310066E14Rik. J Am Soc Nephrol 18: 689-697, 2007. 